\title{
Assessment of the compressive strength of lime mortar in the joints of brick walls - case study
}

\author{
Dawid Łątka ${ }^{1, *}$, and Piotr Matysek ${ }^{1}$ \\ ${ }^{1}$ Faculty of Civil Engineering, Cracow University of Technology, 24 Warszawska Str., 31-155, \\ Cracow, Poland
}

\begin{abstract}
The paper presents the test results of lime mortar compressive strength in the joints of brick walls. The tests were carried out with the Double Punch Test (DPT) method and with the use of an impact penetrometer (penetrometric test PT) on original samples taken from the structure of a building erected in the 1880s. The obtained results have shown that the predictions of the mortar compressive strength using both methods were very consistent (the difference 6\%). The penetrometric method also made it possible to assess the homogeneity of the mortar in the direction of the wall thickness.
\end{abstract}

\section{Introduction}

The most reliable methods of assessing the masonry compressive strength are destructive tests carried out on masonry samples cut out from the existing structure. For the purpose of the study, extracted samples should have dimensions appropriate for the massif of the wall, also sample size should allow for statistical evaluation. However, it is a costly method and cause a significant damage to the structure and therefore can rarely be used. An additional problem is extracting intact samples from the walls. It is especially difficult when samples are taken from the walls on weak mortars. Masonry samples are often stratified and moistened during cutting by the use of water as cooling agent. The transport of larger masonry samples to the laboratory is also problematic. For these reasons, other methods of assessing the masonry strength in existing structure are developed. For example, the masonry compression strength is calculated from empirical formulas on the basis of mortar and brick strength determined in the tests. Taking bricks for destructive testing is usually not a problem. On the other hand, reliable determination of mortar strength in masonry joints is more difficult. First of all, due to the thickness of joints it is not possible taking mortar samples $40 \times 40 \times 80 \mathrm{~mm}^{3}$ compliant with the requirements of EN 1015-11[1]. Therefore, a number of minor destructive methods (MDT) have been developed to assess the mortar strength in masonry joints [2-7]. The penetrometric method presented in this article is used for mortars of low strength, whereas DPT method is used for mortars of cohesion, which allows samples to be cut out of the masonry joint. Other common

\footnotetext{
* Corresponding author: dawid.latka@pk.edu.pl
} 
diagnostic methods worth mentioning are the Windsor Pin Test and the Helix pull-out test [3],[4]. However, these methods are developed for medium and high strength mortars. The advantage of minor destructive methods is the ability to perform a large number of in-situ tests, which is crucial in statistical evaluation. So far, verification of minor destructive methods of testing mortar strength in the joints of masonry walls has been carried out mainly on samples made in the laboratory using modern materials. On the other hand, there are very few test results conducted on real objects. This fact strongly limits the practical application of MDT methods. In order to increase the reliability of the test results, the authors of this article suggested to carry out research using 2 minor destructive methods.

\section{Description of test procedures}

\subsection{Penetrometric test (PT)}

The penetrometric test consists of measuring the immersion of a steel needle in the mortar due to the repeated loading of the needle with a constant force. The view of the penetrometer used in the studies is presented in the figure 1 . The penetrometric test, carried out according to the full incremental procedure, allows assessment of the mortar compressive strength as well as its homogeneity in the masonry joints. The sequence of activities in the case of testing mortar in joints on the external side of the wall (face side) starts with the designation of test points. Then, after cleaning the external surface of the tested joint and possibly removing the repointing layer, the reference needle position is measured. Next, 5-10-15-20 consecutive needle strokes are made (4 series of 5 strokes each) measuring immersion of the needle. On the basis of these actions, the mortar strength can be determined in the joint zone located closest to the external surface of the masonry wall. The testing of mortar in the deeper layers of the masonry starts with the drilling at the tested point a $12 \mathrm{~mm}$ diameter and $100 \mathrm{~mm}$ depth to remove the previously damaged joint material. Then, the reference measurement and steps described above are realized.

The compressive strength of $f_{P T}$ is determined on the basis of a needle penetration expressed in $\mathrm{mm}$, after the tenth impact. The correlation curve given by the penetrometer manufacturer [8] is used.

The homogeneity of the mortar in the direction of the wall thickness is determined using the graphical method, comparing the penetration of the penetrometer needle among the four measuring series. Similar immersion of the needles for series 2 to 4 means satisfactory uniformity of mortar.

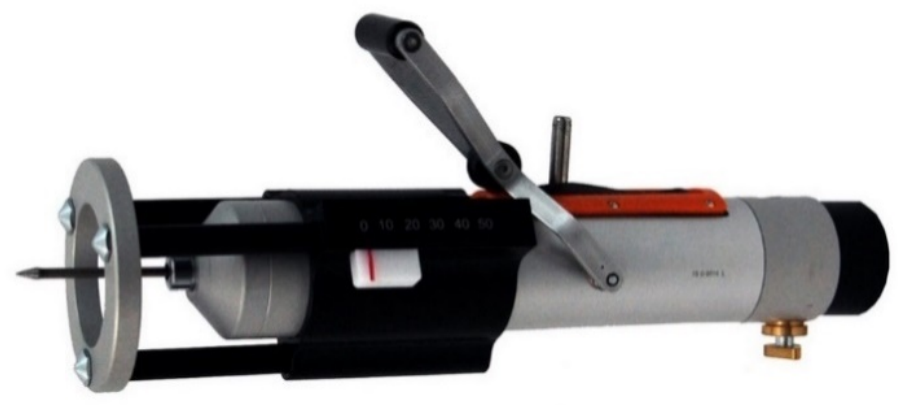

Fig. 1. Penetrometer of RSM-15 version 1.0 of DRC Srl used for testing of mortar in joints of the masonry walls. 


\subsection{Double punch test (DPT)}

The DPT method was first described by Henzel \& Karl in [9]. This method carried out in accordance with DIN 18555-9 [10] and UIC 778-3R [11] has many advantages that have made it very popular. The tested material is taken directly from the structure. The mortar joints are separated from the bricks. Then, irregular mortar samples are cut to regular square form of a side shape of at least $40 \mathrm{~mm}$ (or a circle of identical diameter). Thickness of samples is equal to the thickness of the bed joints. The compressive force is applied by means of steel punches, usually with a diameter of $20 \mathrm{~mm}$. The surface of the sample is levelled with a layer of material (gypsum, mortar) with the strength approximately similar to the strength of tested mortar. The compression load should be applied in a static manner. The test result is the maximum load transmitted to the sample before its destruction. The mortar strength in the DPT test is denoted as $f_{D P T}$ and is determined from the relation (1):

$$
f_{D P T}=F_{\max } / A
$$

where, $F_{\max }$ is the max. load in $\mathrm{kN}$, whereas $A$ is the area of the steel punch.

Due to the fact that the load area is smaller than the surface area of the specimen and friction forces are present at the contact of steel punches with the specimen, the mortar tested by DPT is in a complex stress state. For this reason, the strength of the mortar $f_{D P T}$ calculated from formula (1) may be significantly higher than that determined according to EN 1015-11 [1].

\section{Experimental and results}

\subsection{Samples for tests}

The tests were carried out on $250 \times 260 \times 330 \mathrm{~mm}^{3}$ brick pillar (PT tests) and 26 mortar samples (DPT tests) taken from external walls of a masonry building erected in the 1880s. The building structure was made of bricks $280 \times 130 \times 68 \mathrm{~mm}^{3}$ bonded with lime mortar. The thickness of joints in the masonry was characterized by a great variety. The bed joints were between $12 \mathrm{~mm}$ and $25 \mathrm{~mm}$ thick, while the thickness of the vertical joints was between $7 \mathrm{~mm}$ and $30 \mathrm{~mm}$. The quality of bed joints was assessed as satisfactory. Vertical joints showed numerous voids and local lack of adhesion between mortar and bricks. The brick pillar cutting stage, preparation for testing and heterogeneity of the material in the area of vertical joints are presented in figure 2 .

On the two sides of the brick pillar (the ones that were the external sides of the wall) all joints contain repointing with cement mortar to the depth $25-30 \mathrm{~mm}$. The extraction of the brick pillar made it possible to conduct penetrometric tests of the bed joints located inside the masonry wall and comparison with the results for the measurements of the joints in the facing layer.

Samples for DPT tests were taken from different parts of the structure. The specimens with a height equal to the thickness of the bed joints had a square size of about $50 \mathrm{~mm}$. Prior to the test, gypsum layers with a diameter of approx. $30 \mathrm{~mm}$ were made on all mortar samples. 
c)

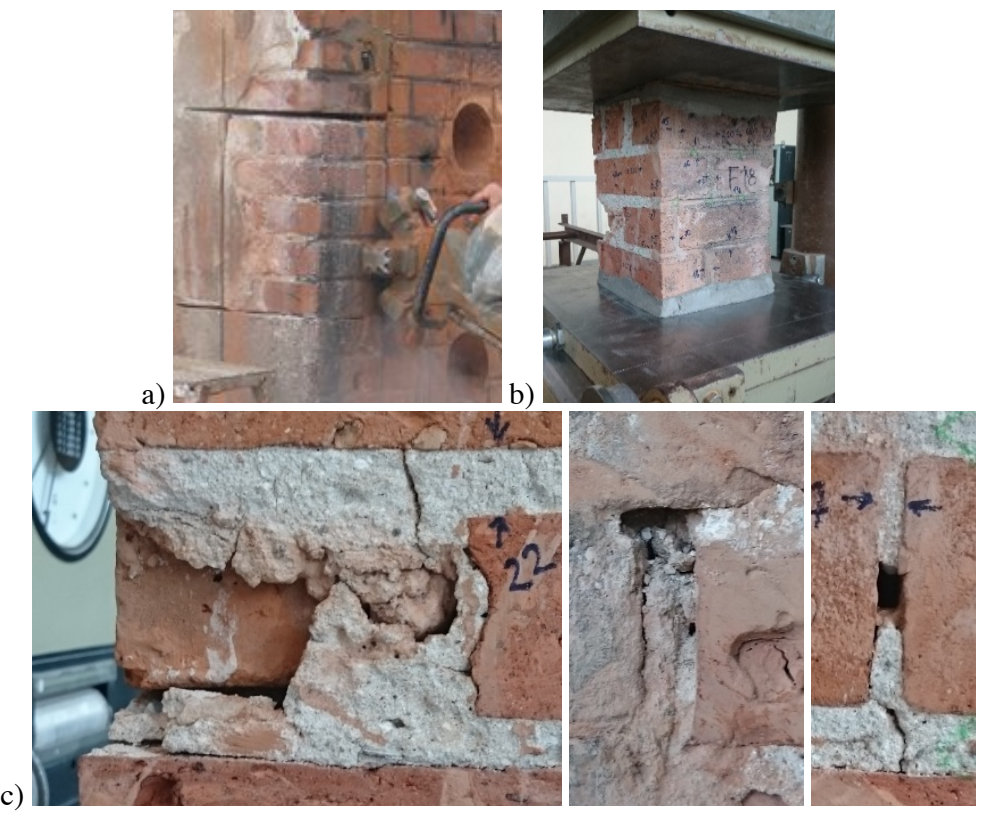

Fig. 2. Tested brick pillar: (a) cutting the pillar from the structure; (b) load induction - 20kN; (c) losses of mortar in vertical joints, local lack of adhesion between mortar and bricks.

\subsection{Penetrometric test on masonry brick pillar}

After seasoning in air-dry conditions, the brick pillar with a $20 \mathrm{kN}$ compression force (corresponding to a compressive stress of approximately $0.3 \mathrm{MPa}$ ) was loaded. The EDU 400 testing machine was used to test. The penetrometric tests were carried out on the bed joints in places far from voids, cracks or intersections of vertical and bed joints. The tests were carried out using RSM-15 penetrometer, according to the methodology described in point 2.1. Tests on external surfaces (2 measuring points marked A-B) and on internal surfaces ( 8 measuring points marked C-J) of the brick pillar were performed. The method of testing was shown in figure 3 .

In figure $4 \mathrm{a}$ the penetration depth increment functions for all measurement series are presented, the results of which did not raise any objections. Two measurement series (marked A and B) conducted on the external surface of the pillar were omitted. Tests have shown that under the repointing cement mortar layer, a degraded original mortar with a loosened structure is located, which resulted in significant penetrometer needle immersions. The remaining 8 series of measurements were carried out on the internal (cut) sides of the brick pillar and thus on the mortar, which was located inside the wall and was not degraded. The mean global value of the needle penetration depth after one impact for all measurements was $1,5 \mathrm{~mm} / \mathrm{impact}$. The greater uniformity of test results for surface measurements (marked on the graph with a continuous line) was observed (see figure 4a). This is due to the fact that surface points were selected in such a way that the results were not affected by any defects as cracks or voids in mortar. Such conditions for downhole measurements could not be observed, thus the results of these measurements have larger scattering (dashed line in figure $4 \mathrm{a}$ vs table 1 ). 
a)
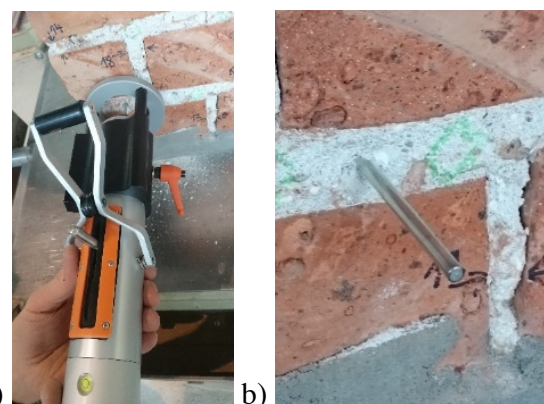

c)
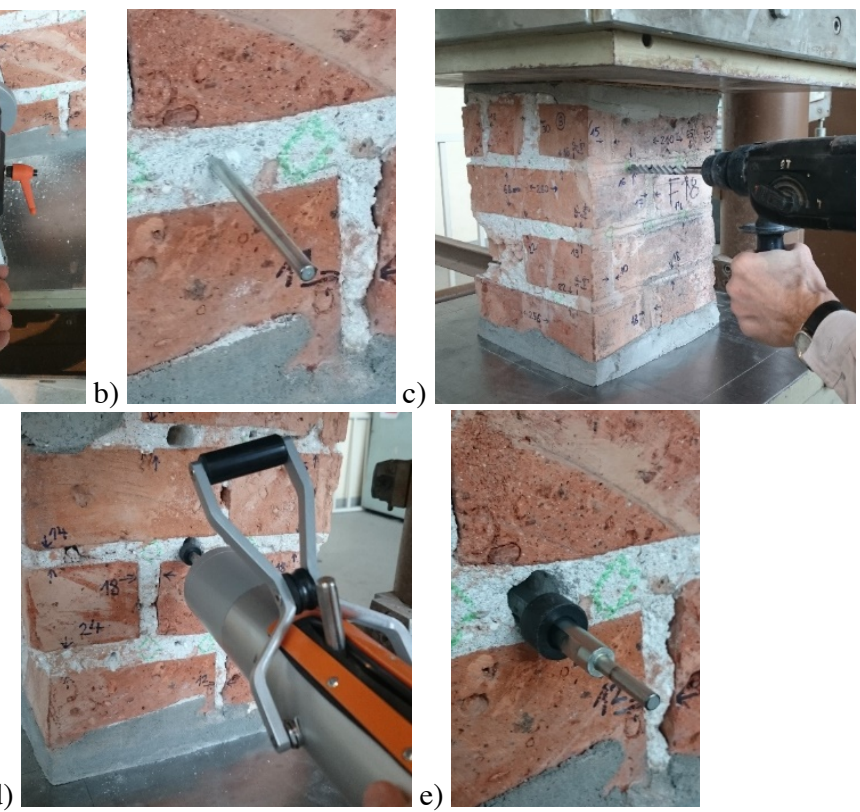

Fig. 3. Testing methodology: (a) penetrometric measurements; (b) location of the needle of the penetrometer after surface examination; (c) dredging of the hole in the test point; (d) penetrometric deep measurements; (e) location of the needle of the penetrometer after the depth test.

Analyzing the penetration distribution (see figure 4b), it should be recognized that the mortar in the bed joints is characterized by high homogeneity, except for zones under repointing mortar. The average compressive strength estimated on the basis of penetrometric tests (table 1) was $2.41 \mathrm{MPa}$ at a standard deviation of $0.48 \mathrm{MPa}$ (coefficient of variation equal 20\%).

a)

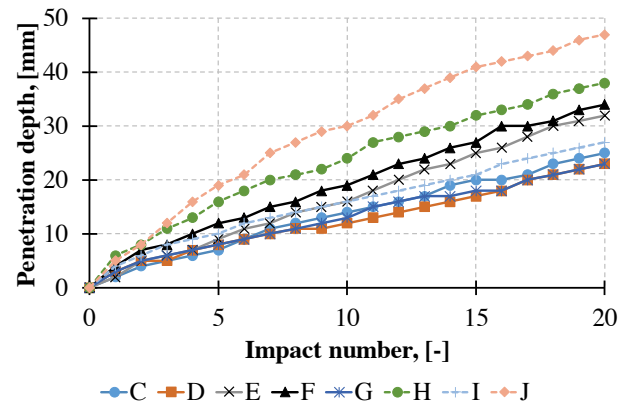

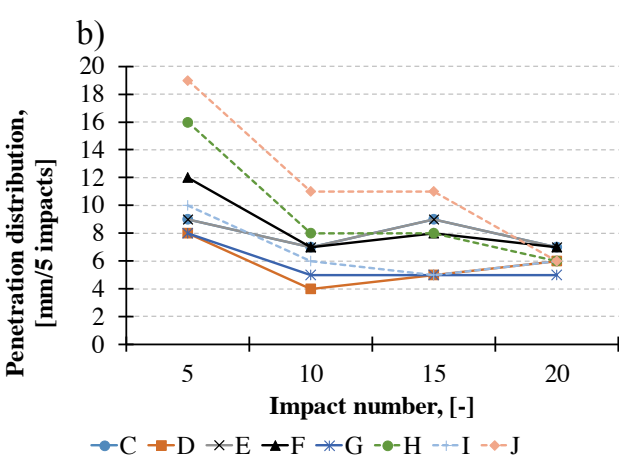

Fig. 4. Results of penetrometric tests (surface measurements - continuous line; downhole measurements - dashed line): a) increase in penetration depth for 20 consecutive impacts; b) penetration depth distribution (4 groups of 5 impacts each). 
Table 1. PT results (10 series).

\begin{tabular}{ccccc}
\hline Measurements & $\begin{array}{c}\text { Strength } f_{P T} \\
\min .-\max .[\mathrm{MPa}]\end{array}$ & $\begin{array}{c}\text { Average } \\
{[\mathrm{MPa}]}\end{array}$ & $\begin{array}{c}\text { Std. deviation } \\
{[\mathrm{MPa}]}\end{array}$ & $\begin{array}{c}\text { CoV } \\
{[\%]}\end{array}$ \\
\hline Surface & $2.32-3.26$ & 2.26 & 0.39 & 15 \\
\hline Downhole & $1.55-2.58$ & 2.07 & 0.42 & 20 \\
\hline Total & $1.55-3.26$ & 2.41 & 0.48 & 20 \\
\hline
\end{tabular}

\subsection{Double punch tests on mortar samples cut out from masonry}

The tests were carried out on the Zwick Roell Z100 in $0.5 \mathrm{kN} / \mathrm{min}$ force control mode. $20 \mathrm{~mm}$ diameter steel punches were used for the test. The tested sample in figure $5 \mathrm{a}$ is presented. The damage of the mortar sample was caused typically by the appearance of radial cracks outside the load area, as shown in figure $5 \mathrm{~b}$.

a)
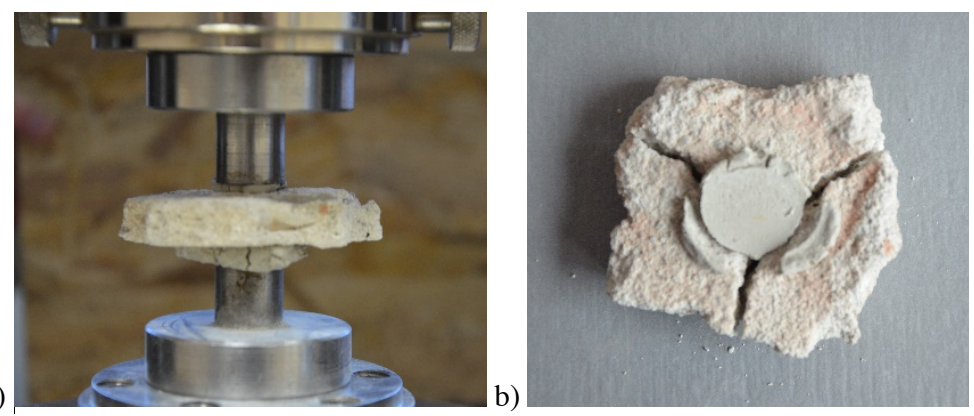

Fig. 5. Testing methodology: (a) DPT test; (b) typical failure mode of mortar sample.

The average mortar strength $\left(f_{D P T}\right)$ obtained according to the formula (1) was $2.28 \mathrm{MPa}$, while the standard deviation $-0.62 \mathrm{MPa}$ (table 2 ). The considerable heterogeneity of mortar in joints is a typical feature of historical structures. The difference in thicknesses between the samples also affected the results. These issues were already the subject of our own research [12] as well as other authors' studies [13],[14].

Table 2. DPT results (26 samples).

\begin{tabular}{ccccc}
\hline Feature & $\begin{array}{c}\text { Strength } f_{D P T} \\
\text { min. - max. }\end{array}$ & Average & $\begin{array}{c}\text { Standard } \\
\text { deviation }\end{array}$ & CoV [\%] \\
\hline $\begin{array}{c}\text { Compressive } \\
\text { strength, } f_{D P T}\end{array}$ & $\begin{array}{c}1.34 \mathrm{MPa}- \\
3.92 \mathrm{MPa}\end{array}$ & $2.28 \mathrm{MPa}$ & $0.62 \mathrm{MPa}$ & $27 \%$ \\
\hline $\begin{array}{c}\text { Thickness of } \\
\text { samples }\end{array}$ & $13.4 \mathrm{~mm}-25.6 \mathrm{~mm}$ & $20.3 \mathrm{~mm}$ & $2.6 \mathrm{~mm}$ & $13 \%$ \\
\hline
\end{tabular}

\section{Comparison of DPT and PT results}

Comparison of the results of the DPT and PT tests for lime mortar strength are presented in table 3 . It is necessary to notice the similar values of all strength parameters. The difference in compressive strength of mortar determined by DPT and PT methods was $0.13 \mathrm{MPa}$, which is a small value from an engineering point of view. A greater difference was made in the standard deviation of mortar strength. This is due to the fact that samples for the DPT test were taken from different points of construction and therefore there is a greater 
dispersion of the test results. Significant dispersions of research results are also caused by the specificity of historical masonry materials. The internal structure of mortar and bricks of the 19th century is definitely different from those used today. The characteristic feature of historical bricks and mortars is the lower homogeneity expressed by the occurrence of numerous structural cracks, as well as inclusions of various materials and aggregates of considerable diameter (figure 6).

a)

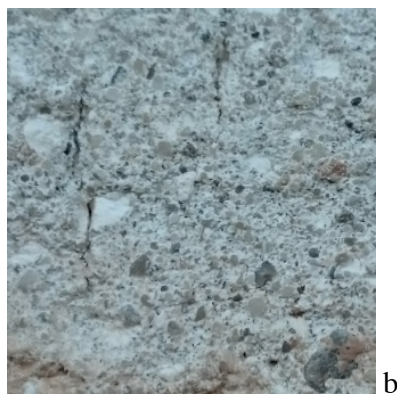

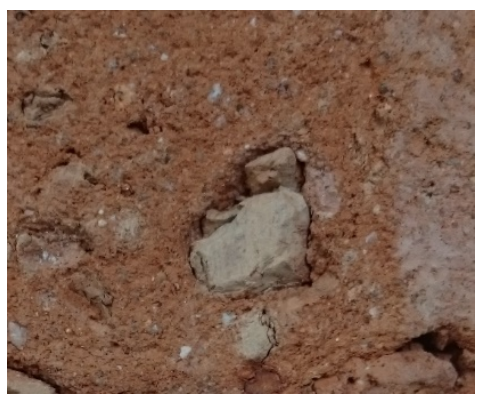

Fig. 6. The internal structure of the tested historical materials: a) typical mortar structure in a bed joint - a stack of aggregates with multiple fractions, including thick fractions; c) typical brick structure - numerous interjections.

In paper [2] it was shown that the compressive strength determined in the DPT test on samples taken from joints with a thickness of $20 \mathrm{~mm}$ is approximately equal to the compressive strength of mortar determined on 40x40x80mm 3 prism specimens. However, this matter requires further research and analysis.

Table 3. Comparing PT and DPT results.

\begin{tabular}{cccccccc}
\hline \multirow{2}{*}{ Test } & \multicolumn{2}{c}{ Strenght } & \multicolumn{2}{c}{ Standard deviation } & \multicolumn{2}{c}{ CoV } \\
& $\begin{array}{c}\text { Value } \\
{[\mathrm{MPa}]}\end{array}$ & $\begin{array}{c}\text { Difference } \\
{[\%]}\end{array}$ & $\begin{array}{c}\text { Value } \\
{[\mathrm{MPa}]}\end{array}$ & $\begin{array}{c}\text { Difference } \\
{[\%]}\end{array}$ & $\begin{array}{c}\text { Value } \\
{[\%]}\end{array}$ & $\begin{array}{c}\text { Difference } \\
{[\%]}\end{array}$ \\
\hline DPT & 2.28 & & -6 & 0.62 & 23 & 27 & 26 \\
\cline { 1 - 1 } & 2.41 & & 0.48 & 20 & 26 \\
\hline
\end{tabular}

\section{Conclusions}

The paper presents the test results of lime mortar strength in joints of brick walls. The tests were carried out on an original brick masonry erected in the 19th century. This is particularly important because the previous verification tests in the field of minor destructive methods were carried out mainly on masonry made of modern materials and therefore they omitted important features distinguishing historical structures.

The compression strength of the lime mortar determined in the penetrometric test (PT) was similar to that of the Double Punch Test (DPT). Differences in mortar strength according to DPT and PT did not exceed 6\%.

Both test methods, the DPT method and the PT method, seem to be useful in estimating the compressive strength and homogeneity of mortars in the joints of masonry. Good results, as shown in the article, can be achieved mainly by compilation of research methods. 


\section{References}

1. EN 1015-11 (2007)

2. E. Sassoni, E. Franzoni, C. Mazzotti, Key Eng. Mat., 624 (2015)

3. L. Pela, P. Roca, A. Aprile, Structural Analysis of Historical Constructions: Anamnesis, Diagnosis, Therapy, Controls.10 (CRC Press, 2016)

4. RILEM Recommendation MS-D.9, Mater. Struct. 30 (1997)

5. RILEM Recommendation MS-D.7, Mater. Struct. 30 (1997)

6. N. Gucci, R. Barsotti, Mater. Struct. 28, 276-283 (1995)

7. D. Liberatore, N. Masini, L. Sorrentino, V. Racina, M. Sileo, O. Alshawa, L. Frezza, Constr. Build. Mater. 122, 810-822 (2016)

8. Penetrometro malta SRM 1.0 user manual - 2015. www.drcitalia.it/en, (February 5, 2017)

9. J. Henzel, S. Karl, Darcon., 2 (1987)

10. DIN 18555-9 (1999)

11. UIC code 778-3 (2011)

12. D. Łątka, S. Seręga, P. Matysek, Structural Analysis of Historical Constructions: An Interdisciplinary Approach 11 (2018) (in revision)

13. M. Drdácký, D. Makšìn, M.D. Mekonone, Z. Slí̌zová, Historical Mortars Conference: Characterization, Diagnosis, Conservation, Repair and Compatibility, (2008)

14. M. Drdácký, Int. J. Archit. Herit. 5, 383-394 (2011) 